\title{
Scientific and Ethical Implications of Human and Animal Cloning
}

\author{
Sidra Shafique \\ Department of Biomedical and Molecular Sciences, Queen's University, Kingston, Ontario, Canada
}

Email address:

s.shafique@queensu.ca

\section{To cite this article:}

Sidra Shafique. Scientific and Ethical Implications of Human and Animal Cloning. International Journal of Science, Technology and Society. Special Issue: Cloning - Scientific and Societal Perspectives. Vol. 8, No. 1, 2020, pp. 9-17. doi: 10.11648/j.ijsts.20200801.12

Received: April 11, 2020; Accepted: April 22, 2020; Published: May 27, 2020

\begin{abstract}
Cloning is an old paradigm with new ethical issues that society is confronting today and will do so tomorrow. In this publication, cloning has been reviewed from the perspective of its broad implications on research, agriculture, pets, sports animals and humans. Reflection of legal status shows a picture of cloning applications that is not only inevitable but expected to change human species forever. Weighing advantages vs disadvantages of either the reproductive cloning or therapeutic one sums up into unnatural acts, changing the diversity of society and risks of exploitation. Modern biotechnology can only clone the genomes, not the individuals. Cultural inheritance comes from the development and adaptation of individuality generation after generation. The biological inheritance may be copied but the cultural inheritance cannot be duplicated. Human cloning infringes upon the principles of individual freedom, identity, and autonomy. Here, the current impacts of cloning are elaborated in comparison to the past and predicting what could happen tomorrow. In any scenario, public discussion and involvement of society must be preceded by making or amending laws and regulations. Risk assessment, enforcing justice and altered explanation of 'words' and 'definitions might be the next stance for bioethicists and lawyers shortly. However, scientists and the regulatory authorities are of the view that the way IVF and animal cloning have been gradually accepted, the fourteen days blastocyst cultivation has been justified, one day the human cloning will also get the approval of a common man. As science will advance, the ethicist and theologists would come up with a favorable argument too, maybe three decades from now. In the present publication, the issue of cloning in general with a focus on human cloning, in particular, is discussed understandably by everyone interested in cloning and its impacts on society.
\end{abstract}

Keywords: Human Cloning, Animal Cloning, Ethical Issues, Reproductive Cloning, Legislation, Cultural Inheritance

\section{Introduction}

People in favor of cloning argue that existence of monozygotic twins is a form of natural cloning, the clone would experience a different environment to grow and won't be an exact copy of the original due to a different oocyte mitochondrial genetic make-up to host the donor nucleus [1]. Still, these arguments do not qualify to counter the 'unnaturalness' of a clone itself. Human genome editing might leave with inheritable human genetic modifications that might pose serious risks and human cloning would have unpredictable effects on future generations. Society is being reshaped slowly by incorporating the cloning, in some way or the other, whether it is through new laws, growing hopes or using emotional aspects as in pet cloning. Undoubtedly, cloning is a very effective research tool helping science not only to understand genetic controls but also to manipulate them. Cultural inheritance must be preserved by looking after genetic code and guarding its manipulation. Ripples of cloning in ethical and psychological frontiers are undeniable, therefore, they must be addressed by everyone at all levels and from all walks of life. Knowing and identifying the question is invariably the first step to analyze and find the solution [Figure 1]. Here we discuss human cloning from the ethical perspective and view the future of this research tool.

\section{Human Cloning}

\subsection{Scientific Journey of Human Cloning}

Human cloning as is understood means 'producing a genetic copy of an existing person'. In fact, human cloning is 
the last outcome in the queue of the genetic manipulation research. The scientific journey has passed through in vitro fertilization (IVF) [2], somatic cell nuclear transfer SCNT for therapeutic purposes [3], generation of cloned stem cell lines for organ production [4], gene editing by CRISPR Cas9 for therapeutic purposes [5] and the latest being successful cloning of the primates. The first report of stem cells created from cloned human embryos - therapeutic cloning- was published in 2013 [3] that was soon followed by the development of embryonic stem cells by SCNT using dermal fibroblasts.[6]. Most recently successful monkey cloning has re-ignited the debate on human cloning. Liu, 2018 have successfully cloned cynomolgus monkeys (Macaca fascicularis) by somatic cell nuclear transfer (SCNT) using fetal monkey fibroblasts. Out of 6 confirmed pregnancies in 21 surrogates, 2 healthy babies were born (Liu, 2018) but still this is the first ever successful primate cloning.

Current applications of SCNT in human therapeutic cloning include using the embryonic stem cells (ESCs) research into the hereditary diseases [7], model systems in assessing drug toxicity [8], and regenerative medicine [4]. ESCs cell lines provide a valuable an unlimited and valuable resource to help find the cure of these inherited diseases. The repository of eighteen human embryonic stem cell (ESCs) line with genetic disorders such as Duchenne and Becker muscular dystrophy, Fanconi anemia, complementation group A, fragile-X syndrome, Huntington disease (three lines), Marfan syndrome etc is available for research into these genetic disorders [7]. These ESC have been established from different sources of embryonic material, including morula, whole blastocyst and isolated inner cell mass. Human embryonic stem cells (hESCs) and induced pluripotent stem cells (hiPSCs) offer sources for generation of an unlimited number of differentiated human somatic cells. These are used as mechanistic models for toxicity testing of New drug discovery (NDD) process especially addressing the species specificity issues [8]. In regenerative medicine, to produce autologous tissue, a large-scale production of homogeneous populations of lineage-restricted progenitor cells is required that can be induced to differentiate into a specific tissue. Ten human embryonic stem (hES) cell-derived mesenchymal progenitor (hES-MP) cell lines have been produced that have the potential to differentiate toward the osteogenic, adipogenic, and chondrogenic lineages in vitro regenerative medicine. [4].

\subsection{Background, Technique and Types of Cloning}

Clones are entities or the individuals that are genetically identical or near identical with the original organism in the context of medicine, biotechnology and molecular biology. A plant physiologist Herbert Webber used the the word 'clon' (without the 'e', from the Ancient Greek word for 'twig') for the first time in the early 20th century [9]. The first successful cloning experiment was conducted in 1962 by transferring the nucleus from one frog cell to a frog egg. In 1994, inducing quiescence or hibernation in a cell, a breakthrough, was achieved in the process of cloning [10]. Wilmut et al., used the quiescence technique in 1996 for the first time on the somatic cell nucleus transferred to the mammalian egg cell and announced the birth of the first cloned mammal, Dolly, the sheep, in February 1997 [11].

Broadly, there is natural and artificial cloning. Identical twins are the example of natural clones in humans and other mammals. There are three different types of artificial cloning: gene cloning, reproductive cloning, and therapeutic cloning. Gene cloning also known as DNA cloning is used to produce multiple copies of single or multiple genes [12]. Reproductive cloning involves the production of a copy of a donor organism by transferring its somatic cell nucleus to an enucleated oocyte or fusing the donor cell such as fibroblast with the oocyte by activation [13]. The zygote is then allowed to grow in vitro to the blastocyst stage and implanted into a surrogate uterus till birth [13]. Therapeutic cloning consists of the somatic cell nuclear transfer of a donor cell to an enucleated oocyte, generating a cloned embryo and using the blastocysts as cell lines or stem cells to generate organs in regenerative medicine or for research purposes [14]. Reproductive cloning and therapeutic cloning involve Somatic cell nuclear transfer (SCNT) technique.

Somatic cell nuclear transfer (SCNT) involves enucleation of the mature oocyte, placement of the donor cell in the perivitelline space, electrofusion of the two cells, activation of the fused cells followed by in vitro culture. The aforementioned is a traditional cloning procedure by which Dolly the sheep was produced in 1996 [11]. In spite of the fact that the genome of the new embryo comes from the somatic donor cell, the cloned animal genome is not identical to the donor cell genome due to the contribution of the mitochondrial DNA in the oocyte (Choi, 2014). The most researched and widely used donor cells are the subcutaneous connective-tissue derived fibroblasts [13]. Fibroblasts are used due to the simple procedure of their recovery and relatively less complicated culture conditions.

SCNT has been modified by removal of zona pellucida (ZP), a layer present around the oocyte, known as Zona pellucida (ZP)-free cloning [13]. ZP keeps the blastomeres in proximity during the embryonic development. Although the removal of the ZP helps in the steps of enucleation and cell fusion, it further needs special culture system to keep the blastomeres compact during embryo development. Therefore, the pregnancy rates are relatively better in the traditional SCNT cloning as compared to ZP-free cloning method due to the better development of an embryo capsule.

\subsection{Legislation/Law}

After successful monkey cloning, are the humans next? The answer to this question lies in examining the legislation and public opinion about human cloning. In general, the advanced countries do not allow human reproductive cloning while some allow the cloning for therapeutic purposes. The U.S. has no federal laws to completely ban the human cloning. Fifteen states ban reproductive cloning and three states prohibit the use of public funds for cloning research [15]. The Charter of Fundamental Rights of the European Union explicitly prohibits reproductive human cloning [16]. Canada bans 
cloning humans, cloning stem cells, growing human embryos for research purposes, and buying or selling of embryos, sperm, eggs or other human reproductive material [17]. According to National Human Genome Research Institute (NHGRI) - a division of NIH (National Institute of Health) USA, indicates that 'NHGRI researchers have not cloned any mammals and NHGRI does not clone humans' [18].

Genome editing and genetic manipulation are the milestones towards human cloning and there are variable, flexible regulations, laws and guidelines that have evolved over the last decade towards their approval. Currently, the regulations governing genetic variation in human embryos vary from almost unenforceable guidelines in Japan, China, India, and Ireland to the criminal charges in Germany [19]. According to October 2018 Nature News Report, Japan has issued draft guidelines on $28^{\text {th }}$ of September to allow the scientists to use the gene-editing tools on human embryos. Before that Japan had unenforceable guidelines like those in China, India, and Ireland [5]. The United Kingdom allowed the research on human hybrid embryos in 2008 after a debate of both ethical and social issues and the bill was passed despite a rebellion by 16 Labour MPs (BBC News, 2008). The aforementioned two examples reflect the transition in the mind of society as the bill was approved by the public representatives.

\subsection{Societal Attitudes}

Societal opinion on an issue as of human cloning might be determined by the public opinion and the stance of the scientific community. Public- Gallup survey (2016) indicates that human cloning was rated by the Americans under "highly unacceptable" category. Data indicate that human cloning is highly unacceptable $(81 \%)$ while animal cloning is somewhat acceptable (60\%). Interestingly, according to the adult American people (2013 survey), the researchers will be using animal cloning to save extinct species $(50 \%)$ and the human would be cloned (48\%) by 2050. (https://news.gallup.com/poll)

\subsection{Scientific Opinion}

The scientific community is of the opinion that "At this early stage, scientists should agree not to modify the DNA of human reproductive cells. Should a truly compelling case ever arise for the therapeutic benefit of germline modification, we encourage an open discussion around the appropriate course of action."[20]. According to the Henry Green, a Stanford University Law professor and Marcy, the executive director of the Center for Genetics and Society in Berkeley University, it is highly condemned to encourage human cloning even for the grieving parents for their late child to save the new child from "the psychological and emotional risks of living under the shadow of its genetic predecessor."[21]. Scientists understand that public approval is important to move forward as of Guoping Feng, a neuroscientist at the Cambridge, "Now is not the time to do human-embryo manipulation," he says. "If we do the wrong thing, we can send the wrong message to the public — and then the public will not support scientific research anymore" [19]. Thus, so far it appears that scientific community apparently is in favor of having the support of public and society for the advancement in human genetic manipulation.

\subsection{Ethical Discussion}

Ethical debate about human cloning is conducted by philosophers, bioethicists, theologists, and lawyers. According to ethicists, cloning violates human dignity, takes away uniqueness, threatens humanity and people are considered as instruments in the process [9]. Still, there are two main groups of ethicists, one being against the cloning with the arguments of playing God, rights to genetic uniqueness and privacy, worthwhile lives, preferences, and side effects to society and to the gene pool [9]. While the other group of ethicists as of Ruth Chadwick, a British philosopher, is of opinion that playing God can be replaced with risk assessment, if genetic uniqueness is not violated in naturally born twins then why it would be violated in clones, side effects to the society could be controlled by law enforcement and the human gene pool will get improved by selection of better traits [22]. Jürgen Habermas, another philosopher, is of opinion that cloning would spell the end of humanity. In his opinion, humans respect each other because of no master or maker relationship exists and clones could never be 'equal' to their own 'makers' [23]. On the other hand, Holms, 1998 argues that the life of a clone would be a 'shadow' of the 'donor' and cannot be the better or even the normal neither psychologically or philosophically [1]. Humans as individuals have been in dialogue with the environment by customizing the environment to their genes and not vice versa resulting in the development of the cultural inheritance. [24].

The opinion of a common man about such a complicated issue is highly influenced by the media, fiction writings and movies. Over the last decade, many movies about human clones have been produced which has portrayed the clones being vulnerable, facing injustice and organ donor instruments only such as Never Let Me Go (2010) [25].

\subsection{Future of Human Cloning}

A glimpse of the future of human cloning can be seen by looking at almost hand in hand evolution of the society and law with the technological advancement. The most recent example is the CRISPR/Cas9 genome editing tool that could be used for germ-line editing in human embryos and might result in 'genetic classism' resulting into the classes in the society that will last for generations [19]. As this technique possess the immense therapeutic benefits it is being researched all over the world in spite of the worst ethical fear that this technology once accepted and advanced could be used for non-medical purposes too.[19]. The US has no federal law on human reproductive cloning; therefore, continuous advancement is expected in near future especially in therapeutic cloning. Organ transplantation is a valid therapeutic and ethical reason for ongoing therapeutic cloning research in regenerative medicine. There are more than 
114000 people waiting for organ transplant only in the US alone, one candidate being added every ten minutes and, 20 people in waiting list dying each day [26]. Although, over last twenty years $80-90 \%$ public opinion disapproves the concept of human cloning as indicated in opinion surveys (https://www.geneticsandsociety.org/topics/human-cloning).

Still, in case the human race arrives at a point where to decide for or against the human cloning, the example of open, early discussion involving scientists, bioethics, regulators and the general public that preceded the UK government's decision to legalize mitochondrial DNA transfer [20] is good to follow.

\section{Animal Cloning}

\subsection{Agricultural Cloning}

Raising the farm animals dates back to 10,000 years ago and agricultural practices such as selective breeding have modified the size and shape of farm animals [27]. Successful mammalian cloning has revolutionized the livestock by changing the landscape of cattle farming [14]. The agricultural cloning has applications such as the rapid propagation of the desired animal stocks and propagating the transgenic livestock [28]. The natural breeding practices have their own advantages such as achieving reliable and consistent rates of genetic improvement for livestock, economically beneficial and no requirement of any expertise. There is no risk in breeding, no time factor or regulatory approval involved. However, some attributes such as the production of hypoallergenic milk or low-cholesterol eggs cannot be achieved by natural breeding. Here comes the role of genetic engineering and the introduction of beneficial genes in the genome of the livestock animals [29]. Mainly, cloning is used in livestock to produce either the cloned embryos by SCNT of high-quality trait animals or to create a transgenic founder animal to further produce clones. The foreign target DNA or genes are incorporated through the transgenic process into the somatic cell genome which is further used as a donor cell. Stem cell lines are then produced by the blastocysts the cloned embryo. For example, Schnieke et al., 1997 used transgenic cloning to produce coagulation Factor IX in sheep milk. Transgenic cells were produced by incorporating a human coagulation Factor IX construct in nuclear donor cells to the enucleated egg [30].

\subsection{Benefits of Agricultural Cloning}

Agricultural cloning allows the breeders to copy and retain the desired and superior performance attributes in cloned cattle, for example, cloning the genetically engineered goat that expresses a lysozyme protein found in human breast milk in the mammary gland and excretes it in the milk [29]. The biggest advantage of the cloning of any type, genre and species is the preservation of the genepool of beneficial, best production traits and environmental adaptability [14]. Cloning is used for the preservation of traits such as genes of healthy and disease-free animals with better immunity. It is a practical approach for the wider dissemination of genetic gain in the livestock industry and cryopreserving the cloned embryos is used as an insurance against the future loss of diversity.[29]. Cloning could enable rapid dissemination of superior genotypes from breeding flocks and herds directly to commercial farmers. Commercial agricultural cloning is a business where guaranteed-live cloned offspring are offered for ten to twenty thousand dollars per calf [29]. Swift production of large flocks enables the availability of an economic amount of agricultural product meeting the high market requirement such as meat market [29].

The ultimate objective of all the transgenic and SCNT technology based livestock projects is to increase the quality and quantity of the valuable products such as milk, meat, wool and fiber with economic benefits and sustainable manner for farmers, processors and the consumers. Although, until the technology is advanced enough to advocate the welfare of cloned animals, the ethical concerns will keep on surfacing [14]. Cloning the selected breeds has application in seasonal farming and farmers could have the choice to select but of multiple clones with each a different but beneficial characteristic [29]. Diversity in such a livestock may become the main concern. Diversity can still be maintained in the commercial livestock through cloning at a large scale as although the donor may be the same for a group of cloned animals, each cloned nucleus is transferred to different oocyte with its unique mitochondrial DNA. This would offer the formation of a herd with diversity but with all better clones [14].

In livestock, cloning has the advantage over the transgenic animal production. In case of the transgenic animals as produced by assisted reproductive technique, the resulting embryo may or may not be of desired genetic background i.e. heterozygous or homozygous while using the donor cell of a transgenic donor for SCNT all the cells of the cloned embryo will have the uniform desired genetic background and all the cells could be used further as the cell line and producing the first generation of animals [14].

By 2050, 10 billion people will populate the planet and it would be possible to feed all only through advanced and improved animal cloning, research into the cloned animal products and help the society to clear all misconceptions about the products coming from the cloned animal [27]. Food consumption has increased over time such as the consumption of turkey has been doubled in last 30 years [27]. In addition to adding the good quality and abundant animal protein into the food chain, the ultimate advantage would be the overall improvement of human health and so the survival. The cloned animal products' have always been questioned by individuals, society and health authorities. The selected genotypes might have the characteristics of production of the specific products, for example, milk with high casein content, more muscular growth with better meat quantity and rapid growth rate [14]. A study conducted in New Zealand (2000-2001) on a farm compared the composition of the milk produced from seven cloned cows derived from one somatic cell donor and the milk from the naturally bred control cows. Results indicated no difference in physical properties, mineral composition, casein, 
proteins, Lactose and IgG between the milk from the two sources [14].

\subsection{Pitfalls of Mammalian Cloning}

Pitfalls of the agricultural cloning can be grouped into the complications of the cloning technique resulting in the animal welfare issues, concerns over the quality of the cloned animal products, loss of diversity by sequential cloning and cost-benefit matters [28]. Other limitations of cloning include very low success rate, gestational complications, and unpredictable long-term health of the cloned animal [31].

Cloning technique itself has complications such as the high rate of pregnancy loss [32], unexpected variation in offsprings [33], large offspring syndrome [31], placental abnormalities [34], dystocia during parturition [31] and high postnatal morbidity and mortality [35]. In 2004, Lee et al., reported high first trimester loss (50\%), second trimester miscarriage (80\%) and the fetal complications of fetal hydrops and fetal overgrowth as well as abnormal placentation in cloned cows as compared to natural breeding practices [32]. Large offspring syndrome refers to the over-size fetus which results in painful and difficult parturition, leading to high rate of operative delivery and occasional death of the surrogate [28]. Unexpected variation in cloned animals occurs due to epigenetic dysregulation occur as SCNT results in perturbations in global methylation patterns and expression of imprinted genes with significant dysregulation of the expression patterns in cloned animals [33]. The imprinted genes play a major role in placental development and early pregnancy loss is attributed to the reduced development of the placental blood vessels [34]. Other gross placental pathologies in the cloned cattle pregnancies include increased placental size due to fused placentomes, extravasated maternal blood within the placentomes and in the interplacental regions and large areas of chrorioallantoic membrane devoid of placentomes [34].

The successfully developed and born cloned animals face the difficulties to acclimatize to the extra-uterine life due to genetic aberrations including abnormalities of telomere length, gene expression and epigenetic changes [31]. The Low postnatal viability of the cloned calves ranges between $47 \%$ and $80 \%$ mainly due to the stressed uterine environment, enlarged umbilical veins and arteries leading to postnatal sepsis [35]. The species-specific lifespan seems to vary and depends on the particular species itself. Dolly, the sheep, died at the age of 6 years and it was speculated that may be one of the reasons was the aging of the donor cell nucleus with telomere shortening. However, the data over the last two decades of hundreds of cloned animals indicate there is no difference in the lifespans of cloned and naturally reproduced animals and no summing up effect in the serial cloning animals as well [36]. To summarize, the main complications of the cloning technique leading to poor outcome are related to animal welfare issues [28].

\subsection{Pet Cloning}

In addition to livestock, the pet cloning is of immense public and commercial interest. The first cloned pet was a deceased 17-year old cat and did cost $\$ 50,000$ to its owner [12]. The aforementioned successful cat cloning was soon followed by first successful attempt to clone a dog in 2005 [32] A recent example of pet cloning comes from the two female pet dogs cloned by Barbra Sreisand, an entertainment industry icon, for $\$ 100,000$. The donor was her late 14-year old dog and donor cells were from the mouth and stomach of the late $\operatorname{dog}[37]$.

The motivation behind the cloning of a pet comes from the pet-human relationship. This particular relationship is well-described in the phrase that dog is the "Man's best friend". Hens, 2009, suggests that human-dog relationships bear resemblance to the family relationships. Humans tend to develop an attachment with their pets similar to their family and friends evidenced by everyday references as 'my baby', 'my best friend'. These attachments result in the involvement to the extent that owners want the cloning of their pets as they expect the clones to be the second edition of their own beloved pet [38]. It is evident in Barbra's example as she stated, "I was so devastated by the loss of my dear Samantha, after 14 years together, that I just wanted to keep her with me in some way. It was easier to let Sammie go if I knew I could keep some part of her alive, something that came from her DNA." [39].

The feeling of friendship with a pet develops from the shared history of the owner and the pet. The cloned pet might be the exact physical copy of the true pet but has no such history, as emotions cannot be cloned so far [40]. Such intense relationships demand the generation of a caring attitude towards the pets by its owner [38], but the process of cloning reduces the pet to an artifact, ends the uniqueness of the pet as if one copy is available, many are to come. Moreover, one cannot build back the lost shared history, as of Barbra, "You can clone the look of a dog, but you can't clone the soul. Still, every time I look at their faces, I think of my Samantha....and smile."[39]. The pet owner would go for pet cloning to get the pet back and enjoy the same experience but this is usually not the case as due to epigenetic and genome imprinting variations the cloned pets are not the true physical copies of the donor [41]. Cloned pets do not always have the same personalities as of lost pets and according to Barbra, "they have different personalities" [37]. This is a vivid example of emotional aspect why the pet owner would go for pet cloning. But still, it is not the same experience.

In addition to failed emotional fulfillment, pet cloning has the ethical issues of animal welfare [41], cost [37] and animal integrity [42]. The success rates in canine cloning are around $4 \%$ with significantly high welfare issues for viable animals [41]. Moreover, it is expensive; ViaGen Pets, a company based in Texas charges $\$ 50,000$ for pet cloning and $\$ 1600$ to preserve the pet's genes. [37]. The cloning of pets seems to be unethical in view of the animal welfare, animal integrity and the end of the emotional relationship. Animal integrity is defined as "wholeness and intactness of the animal and its species-specific balance, as well as the capacity to sustain itself in an environment suitable to the species" [42]. In essence, pet cloning is expensive, the cloned pets are not 
exactly the same even if they phenotypically look the same and it has ethical issues but still affording pet owners may get their pet cloned as businesses are available on commercial basis.

\subsection{Sports Animal Cloning}

Cloning is being used to clone sports animals such as ponies and horses mainly to preserve better performance traits. The horses in polo are called ponies and are as important as riders. Argentina's best polo player, for last 22 years, Adolfo Cambiaso has cloned one hundred horses from several of the best horses [43]. Adolfo has, by now, 14 clones of the gifted 17-year old mare named Cuartetera and plans to have 10 more next year and so on [43].The oldest cloned horses were born in 2003 by somatic cell nuclear transfer and are 14 years old now $[43,44]$. Somatic cell nuclear transfer (SCNT) is practiced as a commercial method of horse reproduction in the United States, Australia, New Zealand and South America [45]. 2 to 5 horse clones are born in Europe per year. The estimated number of cloned horses, all over the world, is US (220), Argentina (126), Brazil (15), Italy (20), Columbia (1), and South Korea (1), making the total around 375 [13]. However, in U.S., multibillion-dollar market of racehorse breeding is controlled by strict laws. Racehorse registering associations such as American Quarter Horse Association (AQHA), the U.S. Trotting Association, and the Jockey Club do not even allow the artificial insemination [46].

Thoroughbred horse racing is against cloning and do not allow the unfair competition factors to be in the horse race business but there is no such prohibition in polo and pony cloning is moving ahead. This raises some questions as whether cloned horses give a team and unfair advantage? Is is ethical to use cloned horses in a game? And most important what lies in the future? The performance of the clone horses did not prove to be above the mediocre and the International Federation for Equestrian Sports (FEI) has approved clone horses registry in 2012 Olympics [45]. It seems that perceptions are being changed over time with better cloning techniques over the participation of cloned horses in racing and sports. In August 2013, a Texas judge gave the ruling against AQHA that was filed on the refusal of the registration of cloned horses [47].

Registration of the cloned racehorses was opposed on the basis of the arguments of inability to identify clone horses but now clones' identification is possible by the unique mitochondrial DNA of the individual oocyte. The cloned animal is not phenotypically identical to the donor animal as well. (Choi, 2014). Interestingly, the Argentina horse registry, the Asociación Rural Argentina (SRA), requires the mitochondrial DNA details to distinguish clearly between the cloned animal and the donor animal [45]. These facts indicate that racehorse cloning is being accepted by society. Equine cloning faces the cloning complications resulting in animal welfare issues such as about half of the live-born foals have been reported to have neonatal maladjustment syndrome, enlarged umbilical cord and leg tendon contractures [48]. However, on cost-benefit basis, the equine cloning is not at that much disadvantage as farm animals' cloning due to less frequent gestational complications such as fetal oversize and dystocia problems during birth [45]. In spite of all the ethical issues, cloning horses is the best available technology to save the breeds and individual genetics of exceptionally gifted sports animals. Overall, it seems that the legislation and society are keeping pace with equine cloning technology and its advancement with slow but steady worldwide acceptance of cloned animals in sports.

\subsection{Other Benefits of Animal Cloning}

In addition to agricultural, pet and sports, the cloning has beneficial applications in reviving extinct species [49] and xenotransplantation [50]. Xenotransplantation, the transplantation of living cells, tissues or organs from one species to another, is the most advanced application of transgenic and SCNT technology. Transgenic human organs grown in the animal embryos with the reduced humoral barrier to organ transplantation [50] and multi-transgenic embryos [51] are the recent advances in this discipline.

\subsection{Legislation and Animal Cloning}

Societal attitudes towards cloning could be assessed by examining the legislation over the issue and the public opinion collected through the surveys. The Legislation is evolving over time about the availability, safety, and consumption of the products of the cloned animals. Main FDA verdicts came in 2001, 2008 and 2015. In 2001, FDA asked the livestock producers to keep food from clones and their offsprings' to be studied by FDA's Center for Veterinary Medicine (CVM). CVM released a report in FDA documents in January 2008 consisting of risk assessment, risk management plan, and the guidance for industry. The risk assessment report states that "cloning poses no unique risks to animal health, compared to the risks found with other reproduction methods, including natural mating' and the composition of food products from cattle, swine, and goat clones, or the offspring of any animal clones, is no different from that of conventionally bred animals, therefore because of the preceding two conclusions, there are no additional risks to people eating food from cattle, swine, and goat clones or the offspring of any animal clones traditionally consumed as food" (https://www.fda.gov/ForConsumers/ConsumerUpdates/ucm 148768.htm). In addition, FDA has not made it mandatory to label the products from cloned animals. In 2015 FDA gave the verdict that transgenic salmon is is as safe to eat as any non-genetically engineered (GE) Atlantic salmon, and also as nutritious. (Commissioner, O., 2015).

Although the regulatory authorities are accepting the cloned animal products over time as indicated by the evolved legislation, the consumer willingness is an important factor too for the current and future acceptance of the agricultural cloning and cloned animals as a source of food products. Recently, Britwan and Bernard, 2018, conducted a field experiment to examine the consumers' opinions and knowledge of animal cloning, views on labeling, and approach 
towards the use of cloning. In this study, four diverse groups of participants (148) were university students (13), natural food store buyers (46), urban farmer's market visitors (47) and people in public parks (42). Results indicated that overall knowledge of cloning was very low $(10 \%)$, one fourth $(22.30 \%)$ had none at all, almost half $(48 \%)$ were of neutral opinion and few $(6.8 \%)$ with the positive opinion about cloning. Although, a good number $(66.21 \%)$ of participants were in favor that milk from cloned cows was acceptable but the demand of labeling $(87 \%)$ the cloned animal products was very high [52].

The low level of knowledge and unlabeled cloned animal products seem the main negative factors in the general approval of cloning being accepted by the consumers as a reliable means of livestock progression. According to one survey, 64\% Americans are against cloning due to animal welfare issues particularly mentioned as of high rate of lost cloned embryos, the suffering of the surrogate due to painful parturition because of the large fetus and placental size, high postnatal morbidity and mortality rates of cloned offspring [53]. In essence, the livestock cloning is a beneficial and practical approach for the present and future development of agriculture, legislation has evolved in favor of the technology but still, the consumer information and acceptance needs to be improved.

\subsection{Societal Attitudes and Future of Animal Cloning}

Review of the current scientific literature, media, and public opinion surveys indicate so far the overall unsupportive attitude of society towards animal cloning on ethical and principle-based grounds. There are anti-cloning associations such as the American Anti-Vivisection Society is a leading animal protection organization that has a website with the campaign End Animal Cloning (https://www.endanimalcloning.org/). The surveys conducted on this website indicate that vast majority $(88 \%)$ of people are against cloning and disapprove cloning for food purposes (66\%) (2006 survey).

Public opinion regarding cloned products varies and is largely based on a low level of knowledge about the technology of cloning and benefits of cloned animals' products. 2007 survey of public opinion polls (https://www.organicconsumers.org/) indicated $89 \%$ of consumers want meat and milk derived from cloned animals to be clearly labeled, $66 \%$ of adults disapprove the animal cloning for food and $66 \%$ are uncomfortable with the cloning techniques used to reproduce animals. According to the 2006 survey, $35 \%$ would never buy the meat products from cloned animals while $59 \%$ would not buy food containing ingredients from cloned animals.

In summary, cloning has the application as an effective animal breeding tool, can be used to preserve endangered species, to produce transgenic animals for therapeutic benefits and maybe getting the pets back. On the other hand, cloning has its own pitfalls including ethical concerns, animal welfare issues during gestation and parturition, high failure rates, expensive procedure, requiring highly skilled neonatal care, post-natal animal health issues, and high mortality rates. With improved legislation, better cloning technique and proven commercial benefits, animal cloning seems to have gradual societal acceptance in the near future.

\section{Conclusion}

In conclusion, despite cloning being successful to a certain extent, there are ethical issues of its application in animal and human cloning. The future survival of human species depends to some extent on preserving genetic variability. To safeguard the diversity in the human race, society must take interest in raising ethical questions and be a stakeholder in formulating laws and regulations. In reality, the policies are the gateways to the future. The media and the educated class of people must think in a way that could help save human consciousness, identity, and self-esteem. As a future direction, the cloning related ethical issues must be taken seriously, kept alive and discussed at all forums.

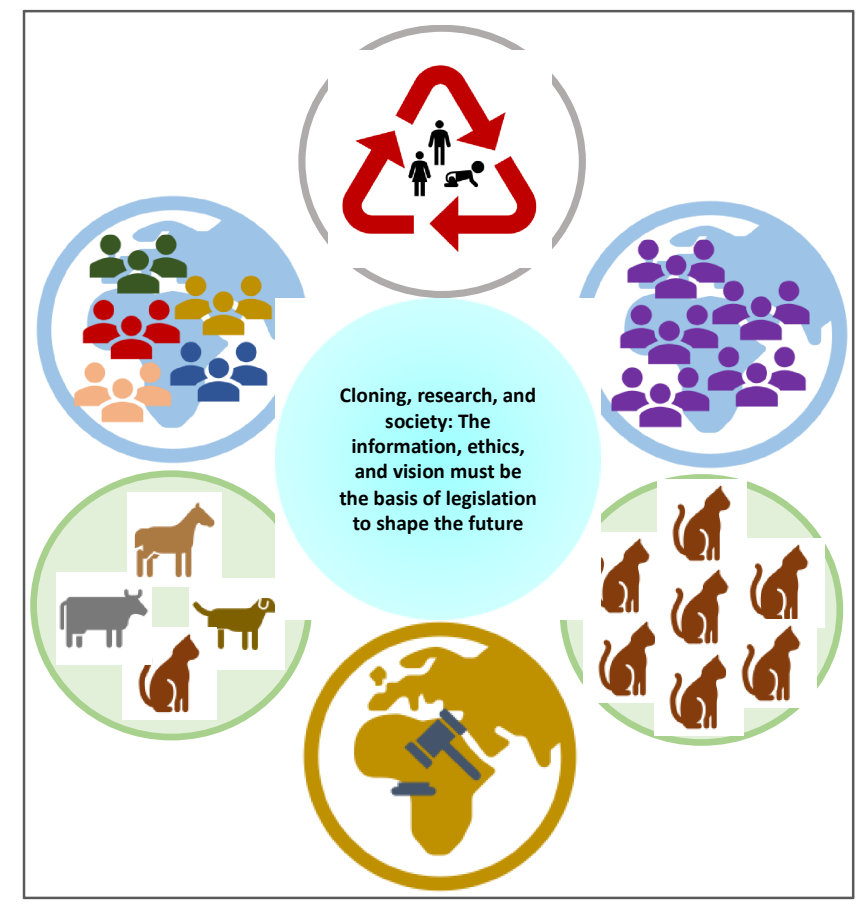

Figure 1. Raising questions: A glimpse of factors manipulating cloning and what society could shape into. Legislation and law are the key still the society needs to share the views, be informed and understand the impacts of cloning at global level to save diversity and cultural inheritance of human species.

\section{References}

[1] Holms, S. (1998). A Life in the Shadow: One Reason Why We Should Not Clone Humans. Cambridge Quarterly of Healthcare Ethics, 160-162. Retrieved from https://pdfs.semanticscholar.org/f560/af8577112c31b9dd230d 5d90fba97f55ae73.pdf

[2] Shanks, P. (2018). The Inconvenient History of IVF - Pete Shanks - Medium. Retrieved March 24, 2020, from https://medium.com/@petereshan/the-inconvenient-history-ofivf-106ea15c378b 
[3] Trounson, A., \& DeWitt, N. D. (2013). Pluripotent Stem Cells from Cloned Human Embryos: Success at Long Last. Cell Stem Cell, $\quad 12 \quad$ (6), 636-638. https://doi.org/10.1016/j.stem.2013.05.022

[4] Karlsson, C., Emanuelsson, K., Wessberg, F., Kajic, K., Axell, M. Z., Eriksson, P. S., ... Strehl, R. (2009). Human embryonic stem cell-derived mesenchymal progenitors-Potential in regenerative medicine. Stem Cell Research, 3 (1), 39-50. https://doi.org/10.1016/j.scr.2009.05.002

[5] Cyranoski, D. (2018). Japan set to allow gene editing in human embryos. Nature. https://doi.org/10.1038/d41586-018-06847-7

[6] Chung, Y. G., Eum, J. H., Lee, J. E., Shim, S. H., Sepilian, V., Hong, S. W., ... Lee, D. R. (2014). Human somatic cell nuclear transfer using adult cells. Cell stem cell, 14 (6), 777-80. https://doi.org/10.1016/j.stem.2014.03.015

[7] Verlinsky, Y., Strelchenko, N., Kukharenko, V., Rechitsky, S., Verlinsky, O., Galat, V., \& Kuliev, A. (2005). Human embryonic stem cell lines with genetic disorders. Reproductive biomedicine online, 10 (1), 105-10. Retrieved from http://www.ncbi.nlm.nih.gov/pubmed/15705304

[8] Shinde, V., Sureshkumar, P., Sotiriadou, I., Hescheler, J., \& Sachinidis, A. (2016). Human Embryonic and Induced Pluripotent Stem Cell Based Toxicity Testing Models: Future Applications in New Drug Discovery. Current medicinal chemistry, 23 (30), 3495-3509. Retrieved from http://www.ncbi.nlm.nih.gov/pubmed/27356535

[9] Häyry, M. (2018). Ethics and cloning. British Medical Bulletin, 1-7. https://doi.org/10.1093/bmb/ldy031

[10] Masci, D. (1997). The cloning controversy, pp. 409-432. Congressional Quarterly, Inc. in conjunction with EBSCO Pub. Retrieved

from https://library.cqpress.com/cqresearcher/document.php?id=cqr esrre 1997050900

[11] Wilmut, I., Schnieke, A. E., McWhir, J., Kind, A. J., \& Campbell, K. H. S. (1997). Viable offspring derived from fetal and adult mammalian cells. Nature, 385 (6619), 810-813. https://doi.org/10.1038/385810a0

[12] Piedrahita, J. A., \& Mir, B. (2004). Cloning and transgenesis in mammals: Implications for xenotransplantation. American Journal of Transplantation, 4, 43-50. https://doi.org/10.1111/j.1600-6135.2004.0344.x

[13] Gambini, A., \& Maserati, M. (2018). A journey through horse cloning. Reproduction, Fertility and Development, 30 (1), 8-17. https://doi.org/10.1071/RD17374

[14] Wells, D. N. (2003). Cloning in livestock agriculture. Reproduction (Cambridge, England) Supplement, 61, 131-50. https://doi.org/10.1079/PAVSNNR20061039

[15] National Conference of State Legislatures. (2016). Embryonic and Fetal Research Laws. Retrieved from http://www.ncsl.org/research/health/embryonic-and-fetal-rese arch-laws.aspx

[16] European Commission. EU Charter of Fundamental Rights (2009). Retrieved from https://ec.europa.eu/info/aid-development-cooperation-funda mental-rights/your-rights-eu/eu-charter-fundamental-rights_en

[17] Philipkoski, K., \& Philipkoski, K. (2004). Canada Closes Door on Cloning. $\quad$ Retrieved from https://www.wired.com/2004/03/canada-closes-door-on-cloni $\mathrm{ng} /$

[18] Cloning Fact Sheet - National Human Genome Research Institute (NHGRI). (2017). Retrieved from https://www.genome.gov/25020028/cloning-fact-sheet/

[19] Ledford, H. (2015). Where in the world could the first CRISPR baby be born? Nature. https://doi.org/10.1038/526310a

[20] Lanphier, E., Urnov, F., Haecker, S. E., Werner, M., \& Smolenski, J. (2015). Don't edit the human germ line. Nature, 519 (7544), 410-411. https://doi.org/10.1038/519410a

[21] Ritter, M. (2018). Scientists successfully clone monkeys; are humans up next? Retrieved April 1, 2020, from https://apnews.com/38beefc3b75745a4b6105d48958a38b5

[22] Chadwick, R. F. (1982). Cloning. Philosophy, 57 (220), 201209. https://doi.org/10.1017/S0031819100050774

[23] Morar, N. (2014). An Empirically Informed Critique of Habermas' Argument from Human Nature. Science and Engineering Ethics, 21 (1), 95-113. https://doi.org/10.1007/s11948-013-9509-5

[24] Ayala, F. J. (2015). Cloning humans? Biological, ethical, and social considerations. Proceedings of the National Academy of Sciences. https://doi.org/10.1073/pnas.1501798112

[25] Hansen, S. L., \& Wöhlke, S. (2016). Contrasting Medical Technology with Deprivation and Social Vulnerability. Lessons for the Ethical Debate on Cloning and Organ Transplantation Through the Film Never Let Me Go (2010). Nano Ethics, $10 \quad$ (3), 245-256. https://doi.org/10.1007/s11569-016-0275-0

[26] Hooijdonk, R. Van. (2018). Human-animal hybrids could one day allow us to grow human organoids inside animals. Retrieved from https://www.richardvanhooijdonk.com/en/blog/human-animal -hybrids-could-one-day-allow-us-to-grow-human-organs-insid e-animals/

[27] Liberatore, S. (2016). What the animals we eat looked like BEFORE humans began breeding them for food | Daily Mail Online. Retrieved from https://www.dailymail.co.uk/sciencetech/article-3459168/Fro m-giant-GM-salmon-buffed-Belgian-Blue-cattle-animals-eat-1 ooked-like-humans-began-breeding-food.html

[28] Ibtisham, F., \& An, L. (2016). Animal Cloning Drawbacks An-Overview. Journal of Dairy, Veterinary \& Animal Research, 3 (4), 3-8. https://doi.org/10.15406/jdvar.2016.03.00087

[29] Van Eenennaam, A. L. (2006). What is the future of animal biotechnology? California Agriculture. https://doi.org/10.3733/ca.v060n03p132

[30] Schníeke, A. E., Kind, A. J., Ritchie, W. A., Mycock, K., Scott, A. R., Ritchie, M., ... Campbell, K. H. S. (1997). Human factor IX transgenic sheep produced by transfer of nuclei from transfected fetal fibroblasts. Science, 278 (5346), 2130-2133. https://doi.org/10.1126/science.278.5346.2130

[31] Hill, J. R. (2002, January). Abnormal in utero development of cloned animals: Implications for human cloning. Differentiation.

https://doi.org/10.1046/j.1432-0436.2002.690408.x 
[32] Lee, R. S. F., Peterson, A. J., Donnison, M. J., Ravelich, S., Ledgard, A. M., Li, N., ... Wells, D. N. (2004). Cloned Cattle Fetuses with the Same Nuclear Genetics Are More Variable Than Contemporary Half-Siblings Resulting from Artificial Insemination and Exhibit Fetal and Placental Growth Deregulation Even in the First Trimester 1. Biology of Reproduction, $\quad 70 \quad$ (1), $1-11$. https://doi.org/10.1095/biolreprod.103.020982

[33] Archer, G. S., Dindot, S., Friend, T. H., Walker, S., Zaunbrecher, G., Lawhorn, B., \& Piedrahita, J. a. (2003). Hierarchical phenotypic and epigenetic variation in cloned swine. Biology of reproduction. https://doi.org/10.1095/biolreprod.103.016147

[34] Miglino, M. A., Pereira, F. T. V., Visintin, J. A., Garcia, J. M., Meirelles, F. V., Rumpf, R., .. Carter, A. M. (2007). Placentation in cloned cattle: Structure and microvascular architecture. Theriogenology, 68 (4), 604-617. https://doi.org/10.1016/j.theriogenology.2007.04.060

[35] Edwards, J. L., Schrick, F. N., McCracken, M. D., van Amstel, S. R., Hopkins, F. M., Welborn, M. G., \& Davies, C. J. (2003). Cloning adult farm animals: a review of the possibilities and problems associated with somatic cell nuclear transfer. American journal of reproductive immunology (New York, N.Y.: 1989), 50 (2), 113-23. Retrieved from http://www.ncbi.nlm.nih.gov/pubmed/12846674

[36] Patrick, J., \& Gottfried Brem, B. (2017). Aging of Cloned Animals: A Mini-Review. Gerontology, 63, 417-425. https://doi.org/10.1159/000452444

[37] Stevens, M. (2018). Barbra Streisand Cloned Her Dog. For $\$ 50,000$, You Can Clone Yours. - The New York Times. Retrieved October 16, 2018, from https://www.nytimes.com/2018/02/28/science/barbra-streisand -clone-dogs.html

[38] Hens, K. (2009). Ethical responsibilities towards dogs: An inquiry into the dog-human relationship. Journal of Agricultural and Environmental Ethics. https://doi.org/10.1007/s10806-008-9120-y

[39] Streisand, B. (2018). Barbra Streisand Explains: Why I Cloned My Dog - The New York Times. Retrieved from https://www.nytimes.com/2018/03/02/style/barbra-streisand-cl oned-her-dog.html?action=click\&module=RelatedCoverage \& pgtype $=$ Article \&region $=$ Footer

[40] Heðinsdóttir, K., Kondrup, S., Röcklinsberg, H., \& Gjerris, M. (2018). Can Friends be Copied? Ethical Aspects of Cloning Dogs as Companion Animals. Journal of Agricultural and Environmental Ethics, $31 \quad$ (1), 17-29. https://doi.org/10.1007/s10806-018-9706-y

[41] Lee, B. C., Oh, H. J., Kim, M., Kim, G. A., \& Park, J. E. (2013). Cloning of Canines. In Principles of Cloning: Second Edition. https://doi.org/10.1016/B978-0-12-386541-0.00021-7
[42] Grommers, F. J., Rutgers, L. J. E., \& Wijsmuller, J. M. (1995). Animal-welfare - intrinsic value - integrity. Developments in the appreciation of the domestic animal. Tijdschrift voor diergeneeskunde, 120 (17), 490-494.

[43] Stahl, L. (2018). The Clones of Polo - Adolfo Cambiaso interview with 60 Minutes on cloned horses - CBS News. Retrieved https://www.cbsnews.com/news/the-clones-of-polo/

[44] Woods, G. L. (2003). A Mule Cloned from Fetal Cells by Nuclear Transfer. Science. https://doi.org/10.1126/science.1086743

[45] Campbell, M. L. H. (2018). Is cloning horses ethical? Equine Veterinary Education, 30 (5), 268-273. https://doi.org/10.1111/eve.12566

[46] Popescu, A. (2017). Horse Clones Start Heading to the Races Bloomberg. Retrieved from https://www.bloomberg.com/news/articles/2017-08-07/horseclones-start-heading-to-the-races

[47] Cockrum, C. J. (2014). Cloning in Racehorses | SLO Horse News. Retrieved from https://www.slohorsenews.net/cloning-in-racehorses/

[48] Johnson, A. K., Clark-Price, S. C., Choi, Y.-H., Hartman, D. L., \& Hinrichs, K. (2010). Physical and clinicopathologic findings in foals derived by use of somatic cell nuclear transfer: 14 cases (2004-2008). Journal of the American Veterinary Medical Association. https://doi.org/10.2460/javma.236.9.983

[49] Wright, D. W. M. (2017). Cloning animals for tourism in the year 2070. Futures. https://doi.org/10.1016/j.futures.2017.10.002

[50] Lutz, A. J., Li, P., Estrada, J. L., Sidner, R. A., Chihara, R. K., Downey, S. M., ... Tector, A. J. (2013). Double knockout pigs deficient in N-glycolylneuraminic acid and Galactose ??-1,3-Galactose reduce the humoral barrier to xenotransplantation. Xenotransplantation, 20 (1), 27-35. https://doi.org/10.1111/xen.12019

[51] Fischer, K., Kraner-Scheiber, S., Petersen, B., Rieblinger, B., Buermann, A., Flisikowska, T., ... Schnieke, A. (2016). Efficient production of multi-modified pigs for xenotransplantation by "combineering", gene stacking and gene editing. Scientific Reports, 6. https://doi.org/10.1038/srep29081

[52] Britwum, K., \& Bernard, J. C. (2018). A field experiment on consumer willingness to accept milk that may have come from cloned cows. Food Policy, 74 (November 2017), 1-8. https://doi.org/10.1016/j.foodpol.2017.10.006

[53] Fiester, A. (2005). Ethical Issues in Animal Cloning. Perspectives in Biology and Medicine, 48 (3), 328-343. https://doi.org/10.1353/pbm.2005.0072 